Original Article

\title{
Education in transdisciplinarity: the training of researchers
}

\author{
Maria Thereza Cera Galvão do Amaral (Vet MD MSc)
}

\author{
Anima-Homeopatia: \\ Consultoria, Assessoria e Planejamento em Homeopatia e \\ Transdisciplinaridade, SP, Brazil
}

\begin{abstract}
The present paper discusses the notions of inter, multi and transdisciplinarity in the context of present day scientific practice, with a brief summary of the historical roots of the current scenario. As a case-study, it is analyzed the situation of research on HDs, as an emergent multidisciplinary field aiming at transdisciplinarity. An illustration is presented, from the experience of the constitution of a multidisciplinary team related to basic research in HDs. The author highlights the specific skills and modalities of participation of both the intervening specialists and the 'generalist' or manager of knowledge. Suggestions are offered on how to expand this model.
\end{abstract}

Keywords: Multidisciplinarity; Transdisciplinarity; Research on High Dilutions; Homeopathy

\section{Introduction}

This paper was elaborated on observations and reflections presented in 2005 by the author at the II World Congress of Transdisciplinarity, based on her personal experience in a group of basic researchers in homeopathy [1]. At that time, studies on both homeopathic clinical practice and the history of science allowed to conclude that fields of knowledge applying epistemological models different from the ones considered standard require a differentiated approach.

In such "twilight areas" of science, experimental results do not fit within the qualitative and quantitative categories of modern science. Analysis strongly suggests that the work of the researchers involved in such fields suffers primarily from problematic theoretical foundations rather than methodological flaws. Indeed, the former are the cause of the latter.

It was also noticed that the academic setting seemed to lack experts fit to transmit to potential researchers such theoretical tools. For this reason, the latter would enter these new fields using the same theoretical foundations and methods as in their earlier work. The result was that they could not understand why they were not able to obtain significant results and when they did, would not know how to interpret them.

What could then be done?

Six years ago, a group of researchers invited scientists from different fields to discuss new perspectives on research problems. The conclusions, related to education in multidisciplinarity by employing a transdisciplinary approach are discussed below.

\section{Contextual framework}

It is necessary to discuss who would be in charge of training in multidisciplinarity, i.e. who would make an effective and efficient mediation in order for a relevant and coherent theoretical body of knowledge to be transmitted to researchers. This discussion should also address the professional levels involved, according to the complexity of each one's knowledge, and an explicit enunciation of the logic underlying the dynamics of the process.

The contents of multidisciplinary education and its corresponding transdisciplinary approach are usually located at the boundaries of fields of knowledge, agglutinate several of them or both. It is not only the researchers themselves who need an access to these contents, but also the teachers. 
This raises several questions: who should be in charge of teaching? How the teachers themselves ought to be trained? As it is hardly conceivable that a researcher will be able to select relevant knowledge, for him or herself and his or her team, without some assistance. On the other hand, it is also hard to imagine that a teacher possessing the required abilities will always be an autodidact, as in the present time. Then, who will?

There is still one more factor to take into account: how to define the individual in charge of spreading of knowledge in a given field, when this requires a general perspective, disdained by the current "dictatorship" of specialism?

How, then, to actually transform the "work of people of different professional levels and different fields of knowledge" in "work-teams" within a context where basic research teams are, indeed, virtually closed?

\section{Scientific scenarios in the 21 st century}

Two individuals, in different places, looking at a same object do in fact see very different things. For instance, a group of cows. A veterinary doctor may see in it cattle herd with a high population density; an ethologist may see an ecosystem altered due to disregard of the basic characteristics of the species. What would happen if both included in a same team?

In "normal" science, there is a belief in the "simplicity of the microscope", i.e. by analyzing or separating a complex object into its parts, it will be found a simple element, a constitutive substance, an essential particle intrinsically more intelligible than the complex whole. Moreover, it is believed that it is possible to get to "learn all" about an object [2]. There is a belief in the stability of the world, i.e. the world is stable and we can know the determinate and reversible phenomena that constitute it, in order for us to be able to predict them and control them. A further tenet is objectivity: more than possible, it is indispensable to be objective when constructing true knowledge of reality.

Therefore, naturally, if the universe is simplified, simplicity will be the result. One who wants to know it or learn how it works employs stability; and when he or she sees it how it "really" is, the result is objectivity.

However, if this approach was possible in the study of living beings in the $19^{\text {th }}$ century, as so-called "scientific biology" was increasingly grounding itself on physics and chemistry - it was proven unfit at the end of the $20^{\text {th }}$ century. Biology was torn between reductionism and non reductionism; the former was the position prevailing among researchers themselves, while the latter was the view of philosophers. In this way, subjectivity continued to rule over philosophy, while matter set the tone of scientific views.

In the life sciences, only scientific knowledge of the human as a biological being was considered legitimate. In the human sciences, on the other hand, the human was considered a social and cultural being. However, while in the physical sciences simplicity, stability and objectivity were possible, the opposite was the case in the human sciences. In the biological sciences, simplicity and complexity were mutually opposed, and reality seemed to favor the latter; stability was opposed to instability and, once again, it was the latter than was observed in the living processes; objectivity was opposed to intersubjectivity, since how it could be possible to exclude the observer from any research?

Before $19^{\text {th }}$ century specialization of science, scholars were able to sail through more than one area or field of knowledge. But this became more and more impossible with the emergence of objectivity and the institutionalization of formal disciplines. In the so-called "new transdisciplinarity" the main problem is the return of subjectivity to each and every field. In this sense, any science is a human science of nature, with no possible exceptions.

\section{"Disciplinarities"}

Contemporary definitions of inter-, multi- and transdisciplinarity are many, according to different views and emphases. In this paper, we address this issue from the perspective of the training of teachers, able to "sail" among disciplines, areas and fields of knowledge.

According to Vasconcellos [2], disciplinarity is a term used to name the division of knowledge into several compartments, i.e. disciplines; multi- or pluridisciplinarity alludes to a juxtaposition of disciplines that do not communicate among them. Interdisciplinarity, on the other hand, will be reserved to the situations where there is some kind of interaction between two or more disciplines, presupposing communication, and aiming at an approximation between them, even at a transference of knowledge.

Finally, transdisciplinarity would represent a later phase, which would locate the links between disciplines within a system, where stable boundaries would no longer exist.

The need for training in transdisciplinary for researchers is illustrated through a case-study, focused on basic research in high dilutions and its practitioners.

\section{Particularities of research in high dilutions}


Whoever chooses to do research in high dilutions, particularly in its fundamentals, will face some problems, at times without an awareness of them. Three of them are highly significant: individual training, requirement of team-work and knowledge in homeopathy.

\section{Individual training}

Basic research in high dilutions requires at least multi- and inter(pluri)disciplinary training in order for a researcher to know how to approach an object of study from different perspectives and to transfer methods from one area or discipline to another. This singular kind of research may frequently involve elements from the history and philosophy of science, semiotics, physics, biology, medicine (humans and animal), botanic, among others. This field requires in particular notions on matter, on living beings and on how to employ differential methods of research.

\section{Team-work}

This kind of research is very difficult, if not impossible to conduct in isolation, without a support team and external consultants. Isolation among areas and research teams is the standard in the contemporary university setting, which concentrates the lion's share of basic research. However, against a wide-spread perception among researchers, the field of high dilutions is too large and the conceptual, structural and methodological crossroads more common than the usual. The structure of "normal" science may give us a false sense of safety, so that many believe that professional closure is not only not prejudicial but even necessary; thus they keep in reserve the discussion of methods and results until they had been published and/or presented in scientific meetings.

However, this kind of discussion is indispensable in order for research itself to advance. Concerning scientific communication, it must be reminded that in this field it requires additional care, due to its polemical nature.

\section{Knowledge in high dilutions}

It needs to be reminded that the field of high dilution research emerged within homeopathy. Homeopathy is an approach to therapeutics and as such, it was designed for doctors, its theory was built and discussed by doctors. Thus, it is only natural that its internal logic might escape non physicians. Its language still needs to be adapted, to be "translated" for researchers trained in other fields.

Therefore, some questions arise: who would make this translation? A translation that must approach the notion of matter, the notion of living beings, the methods to study them and the meeting point between basic research and its application.

\section{Case-study}

A specific setting for favoring exchange among researchers in homeopathy was created in 1988, the double Brazilian Research National Symposium in Homeopathy/Research International Meeting in Homeopathy (SINAPIH/RIM-H). Its seventh (2002) edition was marked by an unexpected twist. The section concerned with basic research made a general impact, due to the quality of the papers presented, the lack of knowledge on the subject and the perception that there was already a critical mass of individuals interested and skilled justifying the need to constitute a group of study. This was also the perception of the organizers of SINAPIH/RIM-H, who asked the researchers involved to form a support group to contribute to the organization of upcoming meetings.

This was the point of departure of an interesting and fruitful process, which resulted in the actual formation of a group, whose activities included periodical meetings and an Internet discussion list. In this case, homeopathy operated as the link among researchers coming from different fields, allowing to sail through boundaries and to learn the languages of borderline sciences.

An aspect that contributed to the success of the project was the model adopted: ideas, projects, works in progress would be presented to be later discussed. The variety of areas, fields and even personal experiences represented were a fundamental enriching factor.

For sure, conflict also arose: some of the participants would exhibit some resistance to an open discussion of work in progress. As mentioned above, to keep silent is a part of contemporary scientific culture. Significantly, this behavior was more remarkable among the older than among the younger researchers.

Perhaps the most important lesson to be extracted from this experience is the need for a group of these characteristics to work up its common discourse and to do it in a rather directed way. This did not happened in this group, interaction tended to be more intuitive that directed and it is highly possible that this was a cause for not making an optimal use of the available time. This points out to the need of a moderator in order to increase the efficacy of this kind of groups. However, this was a highly rewarding experience for all participants, with a net gain in research methodology and in ways to work within heterogeneous teams.

\section{Teaching transdisciplinarity}

Coming back to our focus - transdisciplinarity and teaching -, we have already touched upon the training of researchers, the training of teachers and the training of teachers of researchers, while 
reminding that the latter is crucial, as it will condition the transmission of relevant knowledge by avoiding gaps and theoretical misunderstandings in the training of researchers. We are speaking here of three levels of training, which are differently represented in the present time: if the construction of the level of teachers for researchers is difficult, the one of "teachers of teachers" is almost impossible at the first sight.

A first aspect is that, in order to train "teachers of teachers" prime centers in multi and transdisciplinarity ought to be created, while the training of "teachers of researchers" would require the creation of multi and transdisciplinarity centers in universities and other teaching and research centers. Finally, to train researchers, a reformulation of the syllabi in these same institutions would be needed.

Development of team work is perhaps the most difficult. Basic research involves copyright which requires discretion. However, researchers should be gradually encouraged to build a network of mutual trust, involving scientists from different areas as fields. Brainstorms involving heterogeneous groups result in significant advancements.

Wide-scoped, not immediately evident knowledge in a field of research can be regarded as an asset, as any object of study has some particularities which at times are not perceived or it may required technical knowledge involving more than one area or field. Moreover, at times it happens that a relevant discovery that may help to solve an impasse is made in another area or field

How this can be accomplished? Because it must be accomplished: the reason why no one can know everything is exactly the reason why specialization and institutionalization of disciplines emerged in the $19^{\text {th }}$ century. It is possible to teach methods to find what is needed. And it is possible to learn how to manage knowledge destined to researchers.

\section{Foci of discussion}

Although the main focus in this paper is multi and transdisciplinary training for researchers, not less important are some transversal foci. Education in science, to begin with. It would seem that newer theories on learning do not come too close to the teaching of science in graduate programs. Perhaps this is acceptable in the teaching of "normal" science, but is a serious risk in borderline areas, where a shift in the structure of thought might be required. New pedagogic approaches may be useful in such contexts.

Other significant foci are the history, philosophy and sociology of science, as well as physics, chemistry and biology. To these, several others ought to be added, according to specific fields of actions, and bioethics, permeating them all.

\section{Conclusions}

The professionals in charge of the transmission of knowledge in transdisciplinary training of researchers ought to be teachers with special skills. Their training necessarily requires multi, inter and transdisciplinary studies in order to be able to transmit the grounds of practice to researchers. Professionals trained in this way would be able to seek the tools they need no matter what his or her area of expertise is.

We may think of a teacher like this as someone able to "sift" knowledge and transmit it to others. This is accurate, but it is not all there is. He or she would be able to transmit knowledge in a language researchers from different areas and field would be able to understand, i.e. a "polyglot" in science.

\section{Discussions}

It may be said that nowadays the management of knowledge is indispensable in every area and field. The professional able to do this management is above all a generalist, assisting specialists from different areas. This task involves systemic and complex thinking. It involves management of processes. It involves analysis of scenarios and contexts. The tasks in research involve different qualifications, thus, on the one hand, a researcher would not move at ease in this generalist framework and, on the other, would benefit of professional advice in this sense.

What ought to be the training of a "manager of knowledge"? The immediate answer is: the most general and coherent as possible. Nevertheless, this is a too vague answer. Some suggestions of candidates to fill this position might be historians, philosophers and sociologists of science. These, in principle, would be able to train teachers and researchers able to discern and synthesize the relevant issues without omitting their more general framework.

To conclude, the main challenge for a professional of this kind would be to train teachers able to deal with contents varying according to each particular researcher's needs while avoiding superficiality at the same time.

\section{References}

[1] Amaral, MTCG. Educação transdisciplinar para pesquisadores: o ensino de interfaces. Proceedings of the II Congresso Mundial de Transdisciplinaridade; 2005 Sep 06-12; Vila Velha, Brasil. Brasília: UNESCO/Paris: Centro Internacional de Pesquisa e Estudos Transdisciplinares; 2005. 21-36.

[2] Vasconcellos MJE. Pensamento sistêmico. $3^{\text {rd }}$ ed. Campinas: Papirus; 2003. 


\section{(c)) EY-NC-ND Licensed to GIRI}

Support: author declares that this study received no funding

Conflict of interest: author declares there is no conflict of interest

Received: 15 February 2008; Revised: 17 March 2008; Published: 31 march 2008

Erratum: 30 Dec 2008. (http://www.feg.unesp.br/ ojs/zacha_ijhdr/erratum/?v=7\&i=22\&pi=39)

Correspondence author: Maria Thereza Cera Galvão do Amaral, marithe1@uol.com.br

How to cite this article: Amaral MTCG. Education in transdisciplinarity: the training of researchers. Int J High Dilution Res [online]. 2008 [cited YYYY Mmm DD]; 7(22):39-43. Available from:

http://www.feg.unesp.br/ ojs/index.php/ijhdr/article/view/255/343. 